\title{
CONSERVATION PLAN BASED ON THE CONCEPT OF INTEGRITY
}

\author{
Y. N. Yen ${ }^{\mathrm{a} C}$. F. Cheng ${ }^{\mathrm{a}, *}$ \\ ${ }^{\text {a }}$ China University of Technology, 56 Sec. 3 Shin Long Rd., 116 Taipei, Taiwan - (alexyen, aabbyy)@ cute.edu.tw
}

KEY WORDS: Integrity, conservation plan, risk management, cultural mapping

\begin{abstract}
:
Value based concept has been accepted as a universal principle for the conservation of Cultural Heritage. Authenticity and integrity are two main issues protecting those values. Authenticity is the major tool in the value assessment and integrity plays an important role in the procedure of conservation plan.

From the perspective of integrity, this research explores the principle of conservation plan and discusses its relation with the restoration plan and urban plan. A conservation plan in Quing-Lin village, Kinmen, will be taken as an example for implementation. The research shows that a conservation plan with integrity in mind helps to clarify the conservation target areas and their buffer zones. It also serves as a tool for developing control and risk management. Cultural mapping is an efficient tool for the communication with stakeholders in the process of the conservation plan.
\end{abstract}

\section{INTRODUCTION}

Under the influence of the UNESCO World Heritage program, a value priority concept has been accepted as a common awareness all over the world. Along with it, authenticity becomes a basic indicator for the assessment of cultural value while integrity is an important tool for the implementation of conservation plan. Heritage, the driver of development, is another important issue that turns the conservation process from a static operation into a dynamic one and it helps the sustainability of monuments and historic districts.

Owing to the trend of cultural diversity and variety, public participation has been emphasized as an important issue. An integrative conservation framework will not only involve the cultural heritage authority but also the stakeholders. Under the circumstance, the conservation plan becomes an important platform for the communication among all participants.

When social changes are inevitable, the main goal of conservation plan lies in the intactness of heritages and the ongoing development of the areas. Conservation plan was termed management plan, management system, developing control plan in various documents. Whereas in Taiwan, conservation plans are for monuments and conservation developing plans are for settlements. The goals are similar but the content and implementation process are not the same.

From the perspective of integrity and the significance of the ICOMOS Paris Declaration, the research tries to discuss the basic frame of a conservation plan and the integrated structure of relative plans.

\section{MAIN CONCEPT AND ISSUES}

\subsection{Integrity}

According to article 88 of the Operational Guidelines for the Implementation of the World Heritage Convention (OG), there are 3 required issues for examining the conditions of integrity:

1. includes all elements necessary to express its Outstanding Universal Value; the elements have extended to tangible, intangible properties and their supporting system, organizations and communities.

2. is of adequate size to ensure the complete representation of the features and processes which convey the property's significance; a clear identification of value and proper conservation area is needed.

3. suffers from adverse effects of development and/or neglect; to establish heritage impact assessment indicators, buffer zone and implementation process.

The above-mentioned point 1 can be seen as the plan to conserve the monument itself and similar to the restoration and reuse plan of the article 21 of the Cultural Heritage Preservation Act. Points 2, 3 are mentioned in the conservation plan and can be connected with article 33, 34 of the Act.

\subsection{Protection and management}

There are 10 required issues for the protection and management of the property in the format of a world heritage nomination and can be classified into 3 categories.

1. Main content of conservation plan,

1) Ownership

2) Protective designation

3) Means of implementing protective measures.

4) Existing plans related to municipality and region in which the proposed property is located (e.g., regional or local plan, conservation plan, tourism development plan)

5) Property management plan or other management system

2. Supporting of conservation plan

1) Sources and levels of finance

2) Sources of expertise and training in conservation and management techniques

3) Staffing levels and expertise (professional, technical, maintenance)

3. Interpretation and presentation

1) Visitor facilities and infrastructure

\footnotetext{
* Corresponding author.
} 
2) Policies and programmes related to the presentation and promotion of the property

Since the release of the OG in 2005, there are many advance concepts on the conservation were developed. Cultural heritage economy, developing assessment and control and risk disaster management are just three of them. But none of the three are put into the OG yet. However, these issues have become the key elements of the current conservation plans.

\subsection{Heritage impact assessment (HIA)}

ICOMOS released "Guidance on Heritage Impact Assessments for Cultural World Heritage Properties, HIA" proposing an efficient framework and tools (process, classification, evaluation methods) in assessing the impacts of the Outstanding Universal Value, OUV in 2011. There are limited formal tools for identifying receptors and assessing impact and few examples of excellence for Heritage Impact Assessment (HIA) undertaken for cultural WH properties. However, progress in $3 \mathrm{D}$ virtual representations and digital tools open new means to operating HIA.

Through the procedure of HIA, the significance of the effect of change - i.e. the overall impact - on an attribute is a function of the importance of the attribute and the scale of change. Based on this plan, the monitoring system will have clear indicators to implementation.

\subsection{Disaster risk disaster management}

In addition, UNESCO released $\ulcorner$ Risk management at Heritage Sites- A Case Study of the Petra World Heritage Site 」 in 2012 proposing a procedure for the implementation system of the disaster management which includes context \& scope, identify risk, assess impact of each risk, identify mitigation strategies(preventative or active), evaluate mitigation strategies(risk / cost benefit). There are some other similar documents as well.

\section{THE LEGAL SYSTEM IN TAIWAN}

The Cultural Heritage Preservation Acts (CHA), renounced in 2005, provides a complete legal frame for the lifecycle of monument and site conservation. (Figure 1)

According to CHA, the main goal for conservation plan is to preserve the environment of monument. Through the legal procedure of regional plan, urban plan or national park plan, a conservation or special district can be planned or assigned for the implementation of conservation plan. The content of conservation plan in article 33 of CHA is $\ulcorner$.....the ratio of reserved open space on the sites, the sites' capacity ratios, the depth and width of the front-yard, back-yard, and side-yards on the sites, the appearance, height and coloration of buildings on the sites, and related traffic and landscape matters in such areas may be prescribed by taking..... $\lrcorner$ A basic frame and required factors were described in article 14 of the implementation rule of CHA. Basically, the main concerns of the above-mentioned articles are still from the perspective of visual beauty control. However, some latest important concepts, such as HIA, DCP and risk management are not taken into consideration by current Act in Taiwan.

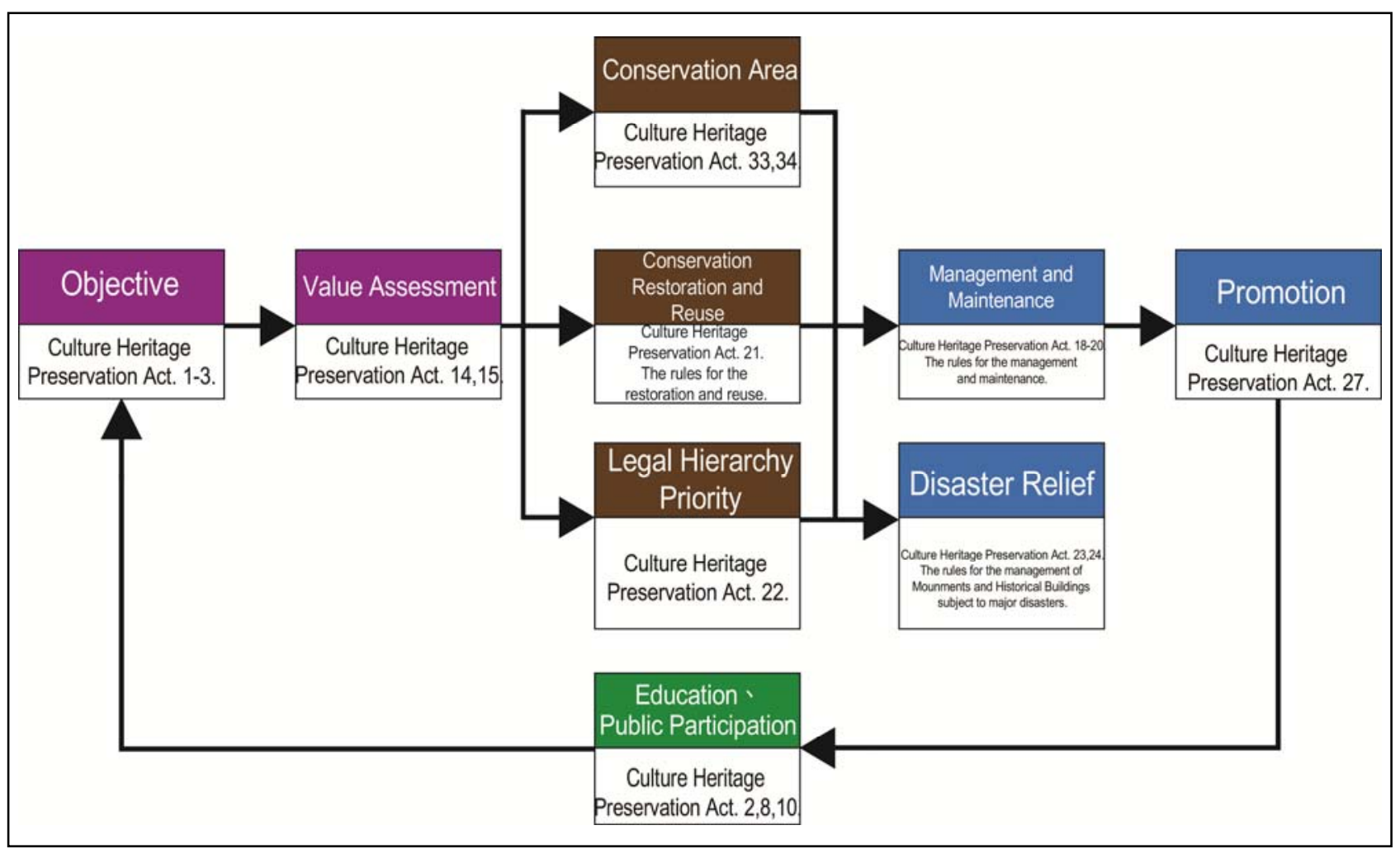

Figure 1. Legal framework for the conservation, Taiwan 


\section{CONSERVATION PLAN}

\subsection{Goal}

In the integrated framework of conservation, aside from the restoration and reuse plan, the conservation plan is another important tool to management of the environment landscape, developing affairs and risk mitigation.

\subsection{Executors}

1. Propose: The cultural heritage authority of local government should integrate the stakeholders to propose the conservation plan together with the restoration and reuse plan.

2. Declare: The authority of regional planning, urban planning and national park planning will integrate the conservation plan into their master plan and declare to the public according to the article 33,34, CHA.

3. Monitor: The local government should establish a monitoring system for the heritage and implement with the stakeholders.

4. Review: The main body of the development (public, private) should prepare a HIA report and review by the local government.

\subsection{The content of conservation plan}

\subsubsection{Basic Concept}

a. The conservation plan should base on the value priority principle.

b. The importance of risk preparedness and mitigation.

c. The importance of the integration of planning and implementation.

d. The importance of the participation of stakeholders.

\subsubsection{The frame of conservation plan}

A. Basic survey and analysis:

a. To review and identify the value of cultural heritages.

b. To analyse relevant laws, existing organizations and plans.

c. To identify risk indicators in the environment.

$\mathrm{d}$. The assessment of resilience.

B. Impact indicators and its boundaries:

For the preparation on the possible restoration, reuse, developing and disaster, an impact indicator system based on value priority concept and their boundaries should be identified.
C. The legal frame for the implementation of conservation plan:

To analyse the legal frame for the implementation of conservation plan, by using special urban zoning process or other methods. The implementation structure can be taken into consideration at this stage.

D. The implementation structure:

How this conservation plan:

a. Integrate with the existing urban plan, building code, fire fighting system etc.

b.Integrate with the community and stakeholders.

c. Prepare a legal process for the reviewing of incoming impacts.

d.Have a long term financial support.

E. Management and maintenance:

a. The management and maintenance in the conservation plan should meet the requirement of Article 20, CHA.

F. Monitoring:

a. To establish the monitoring system and implementation.

G. Relevant drawings and maps:

a. To provide basic drawings and maps such as topographic chart or building survey drawings for monitoring and management needs.

\subsubsection{The impact indicators and boundaries}

HIA is the key issue of the conservation plan and is rarely mentioned in the past. Basically, after the restoration, the monument and its environment are stabilized. However, this situation could be interrupted by the next restoration, the change of reuse, new development or disaster. The possible impacts should have corresponding guidelines and their boundaries in the conservation plan to avoid those negative impacts and encourage positive contribution. The boundaries may consider various impacts such as visual, traffic, usage, rescue etc., through clearly analysis and marks on the proper map.

\subsubsection{Legal and implementation framework}

Each monument should have its own conservation plan and consider if that plan can be applied independently or have to put into the urban plan and make zoning change according to the article 33, 34, CHA. However, all the implementation stage of conservation plans has to integrate with existing plans. The integration frame shows as Figure 2. 


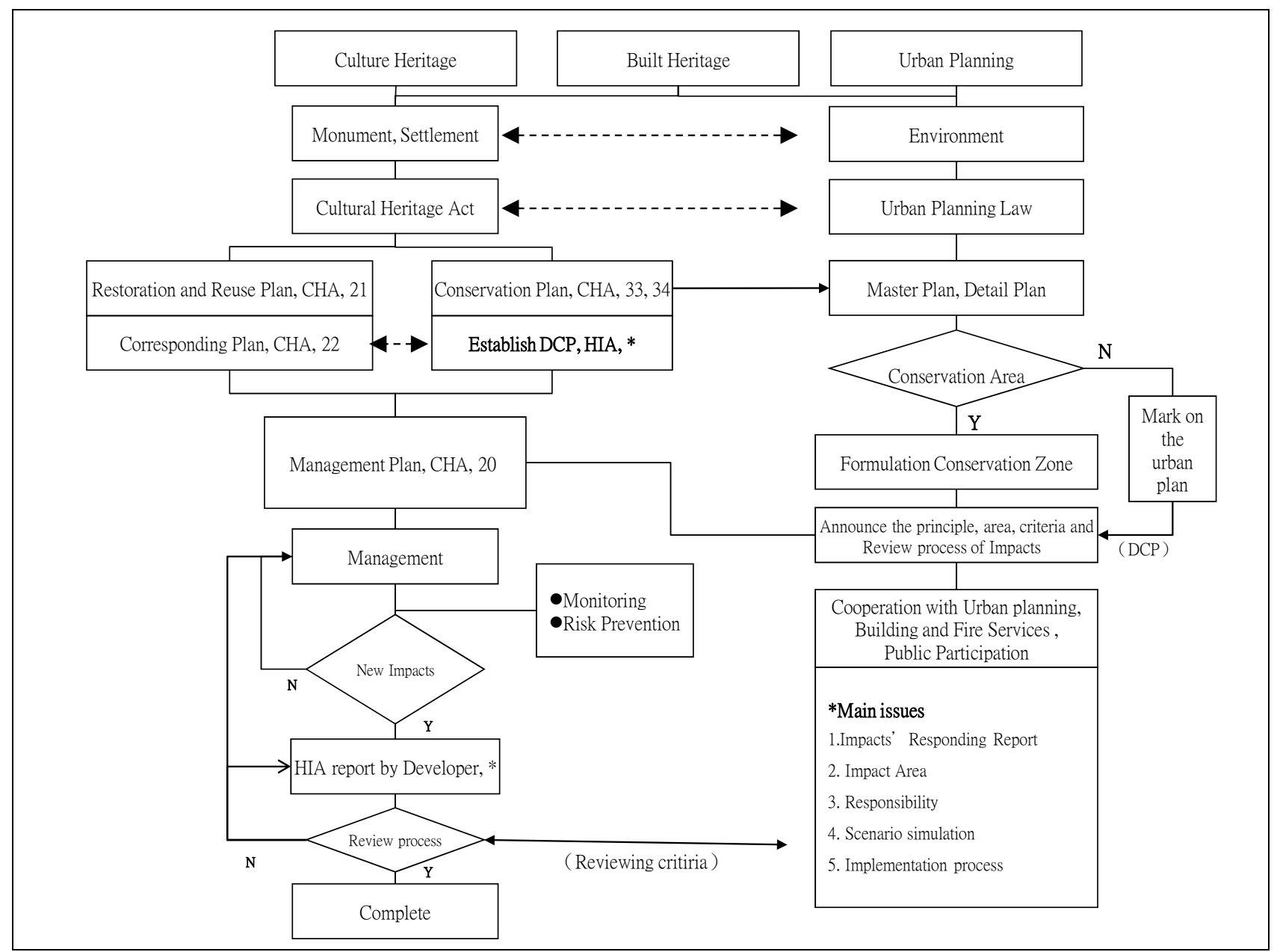

Figure 2. The integration frame of conservation plan in Taiwan

\subsubsection{The monitoring platform and sustain}

1. The monitoring platform should include both public and private sides together with a long term and stable financial support.

2. A monitoring platform needs to acquire analysis and document all the needed information by manual or automatic mechanism. Recently, GIS has been widely used as an efficient tool to help the analysis and presentation of monitoring.

\section{CASE STUDY, QUING-LIN SETTLEMENT, KINMEN}

\subsection{Background}

Quing-Lin settlement is a village with 1,000 years history in Kinmen which has more than 400 traditional houses, 8 ancestor shrines (National Monument) and rich intangible heritages. After this settlement had registered as a monument in 2012, through a 2 years research and public hearing, the conservation plan of Quing-Lin had been proposed.

\subsection{Cultural Mapping}

In the procedure of making the conservation plan, besides the efforts of those experts, to communication and have common awareness with stakeholders is an important issue. In Quing-Lin case, a cultural mapping concept had been taken in the process of understand the value, risk identification, realize of developing pressure, making different conservation approaches and the determination of the conservation area together with the buffer zone. All the stakeholders were invited to participate in the several workshops. Cultural mapping plays an important role to get the common awareness together with the final agreement of the conservation plan.

\subsection{Results}

The process of planning is not only complete the conservation plan but also clarify some important content of the plan as follow.

1. The Identification of conservation targets and their conservation area, buffer zone and appropriate developing area.

2. The adjustment of lows together with the establishment of HIA system and its reviewing procedure.

3. To build an implementation mechanism for stakeholders.

4. To establish an SOP for preparing the conservation plan, this can be applied to other similar villages in Kinmen.

The conservation plan of Quing-Lin village has been sent to the urban planning authority from the cultural bureau already. The 
next step on the management and implementation of the plan will follow the integration frame as figure 2 .

\section{CONCLUSION}

In the era of 21 century, the challenge for the conservation is not only to proceed with the monument or its culture content, but also focus on the additional value resulted from public participation, education and management during the process of conservation. There are many researches on the enforcement of awareness for public participation in conservation. Various topics have been discussed in those papers, such as method, tool, medium, value, assessment, risk management, etc. Moreover, how these efforts can be applied on site? This research finds,

1. Under the concept of integrity, it is convenient to communicate with stakeholders and help to make a proper conservation plan.

2. The idea of avoiding negative impact of integrity can be connected with the risk disaster management idea of UNESCO and put into the conservation plan. The HIA and DCP are efficient tools for the implementation.

3. The integration frame of conservation plan can provide a proper mechanism for the cooperation in different authorities.

4. Cultural Mapping is a useful method in the process identification and communication and it helps to make the conservation plan.

\section{ACKNOWLEDGEMENTS}

Special thanks to the project "Research on the risk communication and resilience of historic district" (MOST 1032625-M-163 -001), sponsored by the Ministry of Science and Technology.

\section{REFERENCES}

1) UNESCO, 《Managing Disaster Risks for World Heritage》, 2010

2) UNESCO and Katholieke Universiteit Leuven, Faculty of Engineering, Raymond Lemaire International Centre for Conservation, 《Risk management at Heritage Sites- A Case Study of the Petra World Heritage Site》, 2012

3) ICOMOS, 《Guidance on Heritage Impact Assessments for Cultural World Heritage Properties》, 2011

4) UNESCO, 《Operational Guideline for the Implementation of the World Heritage Convention》, 2013

5) Ya-Ning Yen, 《Disaster Risk Management and Monitoring for the Cultural Heritage 》, Cultural Bureau of Kinmen County Government, 2014

6) UNESCO, 《Learning with Intangible Heritage for $s$ Sustainable Future》, 2015 


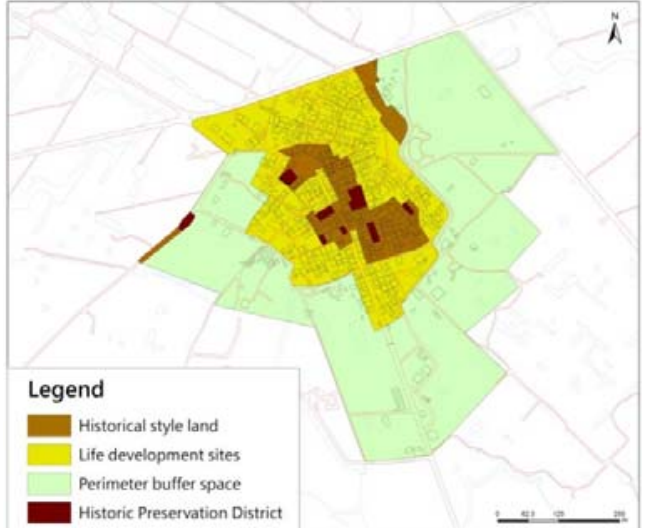

Quing-lin settlement current land use zoning plan diagram

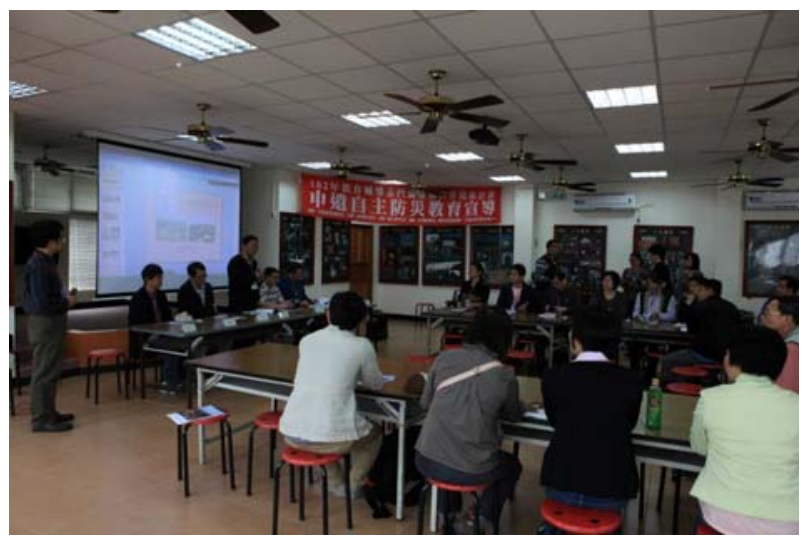

Disaster education advocacy

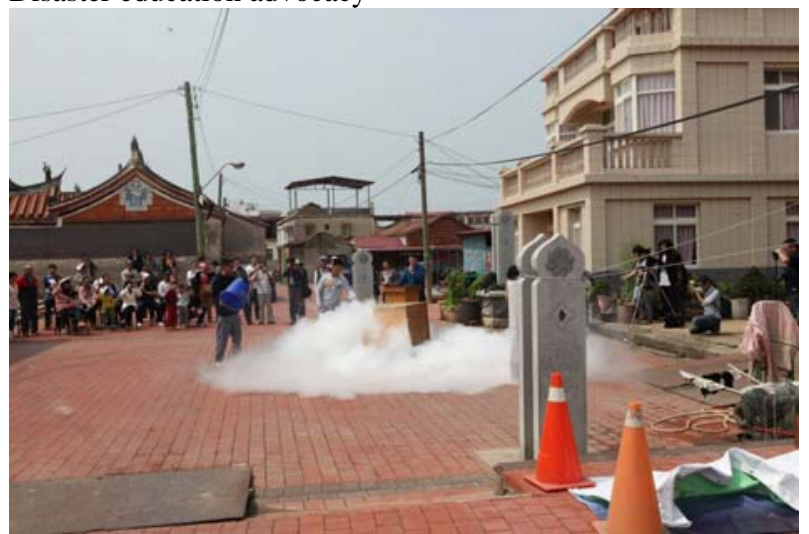

Carbon dioxide fire extinguisher training

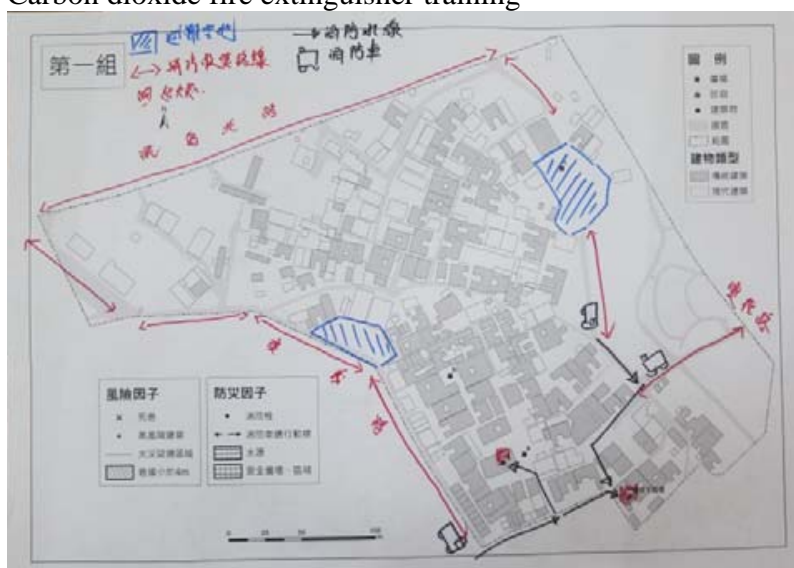

Disaster mapping

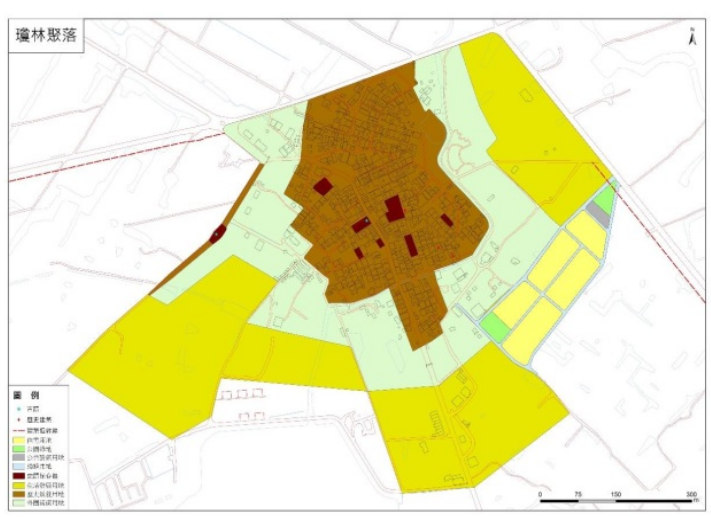

Quing-lin settlement adjusted land use zoning plan diagram

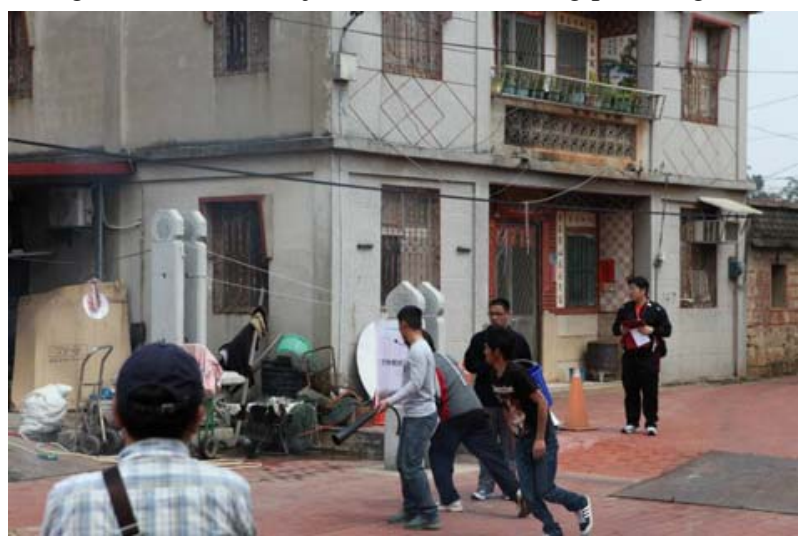

Disaster drills

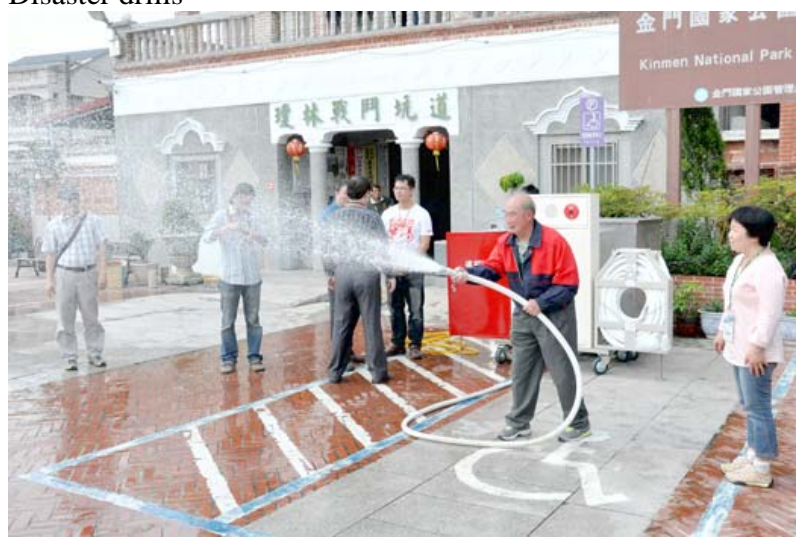

Hydrant training

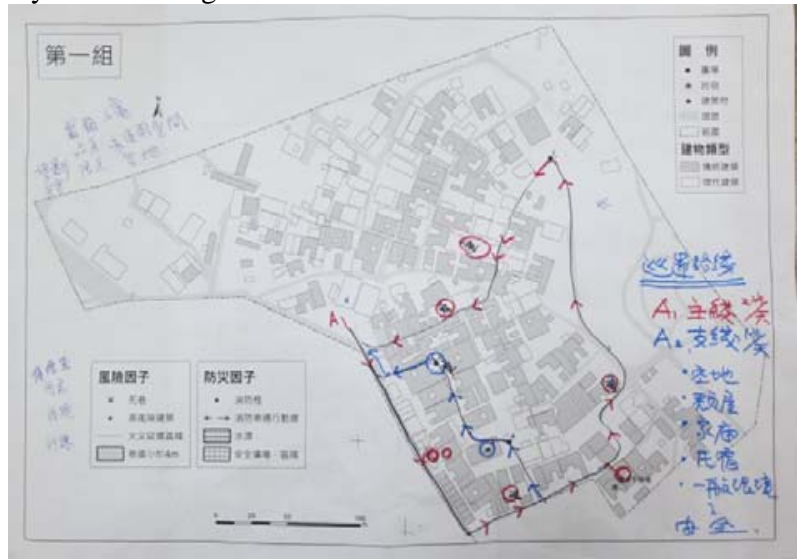

Disaster patrol road mapping 